\section{HUMANASE SOCIAIS \\ V.8・N.3 $2020 \cdot$ Fluxo Contínuo \\ ISSN Digital: 2316-3801 \\ ISSN Impresso: 2316-3348 \\ DOI: 10.17564/2316-3801.2020v8n3p37-50}
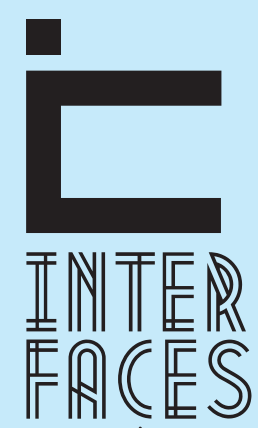

CIENTÍFICAS

\title{
VIOLÊNCIA NA INTIMIDADE DE JOVENS- REFLEXÕES A LUZ DA LITERATURA
}

VIOLENCIA EN LA INTIMIDAD DE JÓVENES - REFLEXIONES A LA LUZ DE LA LITERATURA

VIOLENCE IN THE INTIMITY OF YOUNG PEOPLE - REFLECTIONS OF LITERATURE LIGHT

Daniel Cerdeira de Souza ${ }^{2}$

lolete Ribeiro da Silva ${ }^{3}$

Eduardo Jorge San'Tana Honorato ${ }^{4}$

\section{RESUMO}

Este estudo tratou-se de um recorte teórico de uma dissertação de Mestrado em Psicologia da Universidade Federal do Amazonas e discute o fenômeno da violência na intimidade de jovens com idade entre 15-29 anos a luz de uma revisão de literatura de cunho narrativo em abordagem qualitativa. Analisamos livros, artigos e dissertações que pudessem contribuir com o enriquecimento teórico reflexivo da proposta. Os achados foram analisados a partir de uma perspectiva descritiva e crítica. Os resultados apontam para a violência como um problema de ordem social que atinge o espaço privado das relações íntimas, sendo a violência na intimidade de jovens a expressão da violência de gênero, onde a gravidade da violência tende a aumentar com o passar do tempo na relação. Jovens em situação de violência na intimidade quase nunca procuram ajuda profissional para lidar com essa questão e não saem do relacionamento e quando conseguem sair, acabam por se envolver com relacionamentos abusivos crônicos.

\section{PALAVRAS-CHAVE}

Violência na Intimidade. Jovens. Relacionamentos abusivos.

10 artigo é um recorte de uma dissertação de Mestrado em Psicologia da Universidade Federal do Amazonas, defendido em 2018, a saber: SOUZA, D. C. Relacionamentos abusivos: significados atribuídos por um grupo de jovens acadêmicos da UFAM. 2018. 86f. Dissertação (Mestrado em Psicologia) - Universidade Federal do Amazonas, Manaus. 


\section{RESUMEN}

Este estudio se trató de un recorte teórico de una disertación de Maestría en Psicología de la Universidad Federal del Amazonas y discute el fenómeno de la violencia en la intimidad de jóvenes con edad entre 15-29 años a la luz de una revisión de literatura de cuño narrativo en enfoque cualitativo. Analizamos libros, artículos y disertaciones que pudieran contribuir con el enriquecimiento teórico reflexivo de la propuesta. Los hallazgos se analizaron desde una perspectiva descriptiva y crítica. Los resultados apuntan a la violencia como un problema de orden social que afecta al espacio privado de las relaciones íntimas, siendo la violencia en la intimidad de jóvenes la expresión de la violencia de género, donde la gravedad de la violencia tiende a aumentar con el paso del tiempo en la relación. Los jóvenes en situación de violencia en la intimidad casi nunca buscan ayuda profesional para lidiar con esa cuestión y no salen de la relación y cuando logran salir, acaban por involucrarse con relaciones abusivas crónicas.

\section{PALABRAS CLAVE}

Violencia en la Intimidad. los jóvenes. Relaciones abusivas.

\section{ABSTRACT}

This study is theoretical review of a Master's degree in Psychology dissertation from the Federal University of Amazonas and discusses the phenomenon of violence in the intimacy of youngsters aged 15-29 years as a result of a review of narrative literature in qualitative approach. We analyzed books, articles and dissertations that could contribute with the theoretical enlightenment reflexive of the proposal. The findings were analyzed from a descriptive and critical perspective. The results point to violence as a social problem that affects the private space of intimate relationships, and violence in the intimacy of young people is the expression of gender violence, where the severity of violence tends to increase with the passage of time in the relationship. Young people in situations of intimate violence almost never seek professional help to deal with this issue and do not leave the relationship and when they manage to leave, they end up engaging in chronic abusive relationships.

\section{KEYWORDS}

Violence in Intimacy. Young. Abusive relationships. 


\section{INTRODUÇ̃̃̃O}

Este artigo é um recorte teórico da dissertação de Mestrado referente ao Programa de Pós-graduação em Psicologia da Universidade Federal do Amazonas e tem por objetivo refletir sobre a violência ocorrida na intimidade de jovens por meio de uma revisão narrativa da literatura.

Consideramos “jovem”, pessoas que possuem idade entre 15 a 29 anos, de acordo com o Estatuto da Juventude (BRASIL, 2013). E entendemos que os relacionamentos íntimos são aqueles que mantêm homens e mulheres unidos, independentemente de sua orientação sexual, por terem desenvolvido vínculos sexuais e afetivos. A literatura aponta os impactos e transformações histórico-culturais, com ênfase na vigência do comportamento individualista, das mudanças no papel da mulher, dentre várias outras modificações que contribuem para novas maneiras de se relacionar (COSTA; CENCI, 2014).

Justificamos este estudo por dados que se apresentam em pesquisas anteriores. Em um estudo realizado por Barreira, Lima e Avanci (2013) com 302 jovens, sessenta deles (19,9\%) relataram perpetrar violência física contra os seus parceiros, sendo 37 meninas $(21,8 \%)$ e 23 meninos (17,4\%). Para violência psicológica, a prevalência de perpetração foi de $82,8 \%$, sendo $80,6 \%$ no sexo feminino e $85,6 \%$ no sexo masculino. A prevalência de ocorrência de violência física e psicológica foi de 18,9\%, com $20,6 \%$ para o sexo feminino e $16,7 \%$ para o sexo masculino.

Dados qualitativos também podem ser utilizados para justificar a necessidade desta discussão. As vítimas de violência na intimidade tendem a sentir-se sozinhas, assustadas, envergonhadas, culpadas, desconfiadas, inseguras, confusas, tristes, ansiosas e estes sentimentos são naturais, uma vez que se encontram numa situação complicada de resolver e ultrapassar. Manifestam baixa autoestima, podem apresentar também sintomas de mal estar físico (cansaço, insônias, dores de cabeça, entre outros). Os níveis de ansiedade da vítima podem aumentar pelo fato desta poder reviver cognitivamente o evento de violência do qual foi alvo (MANUEL, 2014; ADEODATO et al., 2005; MOURA, et al., 2009). A partir disso, questionamos: Como a literatura tem discutido o fenômeno da violência na intimidade de jovens?

\section{JUVENTUDE E RELACIONAMENTOS ÍNTIMOS}

Na Psicologia, as concepções de juventude estão fortemente ligadas a estereótipos e estigmas. Ela identifica esse momento como uma etapa marcada por conturbações e tormentos vinculados a emergência da sexualidade, inserção profissional e conflitos de identidade. A juventude, vista de modo naturalizado é encarada como um "estado" influenciado por parâmetros biológicos comuns a todos os jovens e não como uma condição social, desconsiderando-se a inserção histórica e cultural do sujeito (CONTINI; KOLLER, 2002).

Rompemos com essa perspectiva que naturaliza e generaliza as vivências da juventude. Aqui os jovens são entendidos como sujeitos que representam e apresentam suas próprias questões para além das expectativas sociais, rompendo com a ideia de que a juventude é um período de natural de crise, antes, compreendendo esse período como um momento rico em possibilidades. 
As relações afetivas sofrem inúmeras mudanças por meio do tempo. As influências advindas pela ótica judaico-cristã ajudaram a constituir a noção de casamento como como união sagrada e ainda hoje, percebe-se que o imaginário populacional possui um desejo idealizado por noções como "até que a morte os separe”. As mudanças nas definições de família também vêm influenciando a maneira como os relacionamentos afetivos em um processo contraditório, onde relacionamentos mais abreviados e instantâneos se mostram incompatíveis com a família tradicional calcada na aliança de amor e união eterna (JUSTO, 2005).

Com a flexibilização das relações íntimas, observa-se novas maneiras de relacionar-se. Tudo começa no que define-se como "flerte ou paquera", que é um repertório de conquista do jovem. É um jogo emocional extremamente individual, pois cada um tem uma maneira diferente de flertar, podendo envolver olhares insinuantes, uma piscada de olhos e afins, porém a finalidade é demonstrar interesse afetivo sexual no outro. É uma espécie de ritual social, aprendido por experiência vivida e dependendo das particularidades do indivíduo, este vai ter mais facilidade ou dificuldade nesse processo (DE JESUS, 2005).

Usa-se a expressão 'ficar' para caracterizar uma fase de atração sem maiores compromissos e que pode envolver desde beijos até contatos sexuais (RIBEIRO et al., 2011). Há a possibilidade de existir continuidade (ou não) neste tipo de relação ( $\mathrm{SCHUCH,} \mathrm{1998).}$

O namoro é caracterizado pela estabilidade da associação entre duas pessoas, que é inversamente relacionado à probabilidade que uma pessoa vai deixar o relacionamento. Refere-se à adesão de uma pessoa a uma relação específica mesmo quando fatores ambientais se interpõem contra a associação. Essa relação íntima estabelece um laço que confere segurança emocional neste momento de distanciamento das relações parentais. Considera-se que a capacidade de construir e manter relações íntimas constitua um dos principais critérios de saúde mental e de satisfação interpessoal (BERTOLDO; BARBARA, 2006).

Outro ponto interessante a ser pensado é o poliamor, que, colocando o amor como centro das relações afetivas, o poliamor nasce do entendimento de que o amor não pode ser forçado, direcionado ou impedido de ser sentido. 0 poliamor defende, assim, que é possível e válido manter relações íntimas e/ou sexuais com múltiplos parceiros simultaneamente, com a concordância de todos os envolvidos (PEREZ; PALMA, 2018).

\section{MÉTODO}

Esta é uma revisão de literatura narrativa (não sistemática) com caráter descritivo. Esse tipo de pesquisa busca a resolução de um problema por meio de referenciais empíricos e teóricos publicados (PIZZAl et al., 2012). Esse tipo de estudo consiste na revisão de determinado assunto sob a análise crítica do autor (ROTHER, 2007).

Conforme o problema apresentado utilizamos livros, artigos publicados em periódicos, dissertações e teses que fizessem sentido a nossa proposta, estando estes datados livremente. A busca dos dados (artigos, teses e dissertações) foi realizada por meio de publicações com resumos disponíveis e indexa-

Interfaces Científicas - Aracaju • V.8 - N.3 • p. 37-50 • $2020 \cdot$ Fluxo Contínuo 
dos na internet. Para a coleta dos livros, utilizamos a biblioteca central da Universidade Federal do Amazonas. Os dados colhidos foram analisados e interpretados de forma descritiva e crítica. 0 método descritivo tem como objetivo organizar, resumir e descrever conteúdos relevantes mais observados (REIS; REIS, 2002). Na análise crítica de dados, o pesquisador preconiza e formula um juízo crítico, tomando uma posição e atitude reflexiva sob o que leu (GIL, 2002; PRODANOV; DE FREITAS 2013).

\section{RESULTADOS E DISCUSSÕES}

\subsection{VIOLÊNCIA NA INTIMIDADE DE JOVENS}

A violência de gênero sustenta a violência na intimidade. Essa violência é aquela que é exercida de um sexo sobre o sexo oposto baseada nas diferenças entre estes. 0 conceito refere-se à violência onde 0 sujeito passivo é a pessoa de gênero feminino (OLIVEIRA; PAES, 2014; SILVA; COELHO; CAPONI, 2007).

A violência nas relações entre jovens é expressão clara da violência de gênero, pois se caracteriza por atos que geram danos físicos ou emocionais, perpetrados com abuso de poder de uma pessoa contra a outra, que acontecem em relações desiguais e assimétricas, produzidas por normas de gênero que naturalizam as noções de masculino e de feminino (OLIVEIRA et al., 2016).

No ficar, como não há obrigatoriedade de fidelidade, observa-se a manifestação da violência por meio das exigências de um parceiro para com o outro, por exemplo. Noções como exigir a exclusividade sexual de um parceiro enquanto este outro não a mantém pode ser considerado uma forma de violência. O que justifica essa exigência é a noção egoísta de dominação de um parceiro sob o outro. É um tipo de forma de controle que permite a liberdade sexual apenas de um parceiro (geralmente o homem) mesmo não havendo comprometimento entre os dois. As expectativas de um sobre o outro, podem ser motivadoras de comportamentos controladores, portanto o "ficar abusivo" pode ser bastante comum.

Já no namoro, a violência é um comportamento dentro de uma relação íntima que causa dano físico, sexual ou psicológico, incluindo atos de agressão, coerção sexual, abuso emocional e comportamentos controladores (MURTA et al., 2013).

A partir da revisão de literatura, observou-se que a maioria dos estudos sobre abuso nas relações juvenis abordam a figura masculina como perpetradora da violência e a mulher como vítima, porém essa visão é contradita em estudos que se debruçam sobre jovens, onde os relatos permeiam uma relação de violência mútua (LEVY; GOMES, 2008; ALVIM; SOUZA, 2005; ROSA; FALCKE, 2014; CARIDADE; MACHADO, 2006). Fato curioso é observar que a agressão física feminina contra o masculino representa para as jovens, a recusa em ocupar um lugar submisso frente ao parceiro, produzindo reações fisicamente violentas às investidas opressoras, controladoras e agressivas por parte do parceiro (OLIVEIRA et al., 2016).

A ideia da mulher sendo violenta é difícil de ser assimilada, pois isso vai contra o estereótipo da passividade e desproteção feminina construído pelos estereótipos de gênero. Na diversidade dos relacionamentos jovens, as agressões são mútuas e a vítima muitas vezes encara-as erroneamente como demonstrações "normais" de ciúme, minimizando e naturalizando, assim, os episódios de violência 
(MANUEL, 2014). A agressão física de autoria feminina é justificada por ser uma forma de revidar outra agressão vinda do masculino. Essas agressões são consideradas banais, pois não trazem danos significativos aos seus parceiros (OLIVEIRA et al., 2016).

A literatura mostra que as mulheres sempre foram tratadas pelos homens com base na violência, assumindo um papel de subordinação. Muitas mulheres, em algum momento das suas vidas, terão estado ou estarão inseridas numa relação abusiva que envolve atos de violência (CARIDADE; MACHADO, 2006). Um relacionamento abusivo é marcado pela tentativa de controle excessivo que um parceiro tenta exercer sobre o outro com o objetivo de isolá-lo para si, sendo permeado por diversas formas de violência (MURTA et al., 2013; COELHO, 2018).

Segundo Krug e outros autores (2002), o comportamento controlador refere-se a comportamentos com intuito restritivo de um parceiro contra o outro. Estes, muitas vezes evidenciam o sentido de subordinação feminina, mas tais situações muitas vezes não são consideradas pelos jovens como violência, enquanto não atingem um nível de obsessão. Entretanto, apesar de não parecem violência, elas atingem o sujeito que sofre o controle e trazem muitos danos para a saúde.

A violência nos relacionamentos juvenis, na maior parte das vezes, começa por meio do controle psicológico para, posteriormente, evoluir aos outros tipos de violência. Essa última surge geralmente em resposta a não sujeição ao controle, ou seja, quando um parceiro não se submete ao outro, as outras violências surgem como tentativa extrema de manter a homeostase da relação (GUARESCHI MATTES; FACCO ROCHA, 2016). Jovens envolvidos em violência na intimidade - vítimas ou perpetradores - geralmente não procuram ajuda profissional. Entre os jovens brasileiros, a maior parte deles convive com tipos diferenciados de violência nas relações amorosas, especialmente violência psicológica e sexual (OLIVEIRA, 2014; SOARES; LOPES; NJAINE, 2013).

Entre os jovens que se envolvem em vários relacionamentos violentos, a gravidade da violência tende a aumentar a partir da primeira para relações posteriores. Jovens que tiveram um relacionamento abusivo eram mais propensos a se envolver em um posterior relacionamento do mesmo tipo (tornando esse fenômeno crônico), do que aqueles que não tinham vivenciado violência em relacionamentos anteriores (OLIVEIRA, 2014; BESERRA et al., 2016; OLIVEIRA et al., 2016).

Muitos jovens afirmam que algum comportamento abusivo possa ser aceito, como, por exemplo, o controle do outro por meio da censura de roupas e telefonemas e cerceamento da liberdade. As atitudes controladoras estão também relacionadas a um compromisso com o parceiro e é frequente que vítimas de agressões confundam atos controladores e ciúmes com atenção, prova de amor e preocupação por parte do perpetrador (DIXE et al., 2010).

A perpetração da violência e a vitimização compartilham, em parte, os mesmos fatores de risco, como testemunhar violência entre os pais, ser vítima direta de violência pela família, sofrer abuso sexual, conviver com pessoas que são violentos com seus parceiros, ter crenças machistas, aceitar a violência como meio natural de resolução de conflitos e ter déficits em habilidades sociais assertivas ou de manejo da raiva e autocontrole emocional (MURTA et al., 2013).

A violência entre jovens no namoro é semelhante à violência doméstica nos adultos e tende a aumentar ao longo da duração da relação (MANUEL, 2014). Inúmeros estudos sobre violência conjugal 
apontam o início das agressões na fase de namoro e no período da formação universitária encontramos a maior incidência da formação de casais e o início da constituição de famílias, o que pode determinar um padrão de relacionamento ao longo do ciclo vital (ALDRIGHI, 2004).

Nas relações de abuso, é comum a explosão da violência física após uma série de maltratos psicológicos anteriores (ROSA; FALCKE, 2014). A violência psicológica é refletida, tendo como parâmetro os limites e regras de convivência, sendo complicadas não só sua identificação por terceiros como também a sua denúncia, visto que não possui materialidade. A violência verbal como extensão da violência psicológica é a que mais ocorre nas relações entre os jovens e enfatizam que a sua elevada frequência contribui para que esta seja banalizada, porque é comum e aceitável em algumas situações (BESERRA et al., 2016).

O abuso emocional tem origem no desejo do/a agressor/a controlar o comportamento da outra pessoa, tentando dessa forma diminuir a sua autoconfiança e limitando a sua capacidade de agir. Relativamente a este tipo de agressão é tão frequente em homens como em mulheres, porém, os homens estão mais propensos a aumentar a intensidade do abuso quando sentem que estão a perder o controle, podendo mesmo recorrer a violência física (MANUEL, 2014).

A violência psicológica contribui para o desgaste das relações e, de tanto se repetir, torna-se "natural" além de ser o tipo de violência, juntamente com a coerção sexual, mais comuns nos relacionamentos entre jovens (ALVIM; SOUZA, 2005; CARIDADE; MACHADO, 2006).

Sobre a violência sexual, esta é silenciada e invisibilizada do ponto de vista social pelos estereótipos de gênero, onde "o homem não consegue se controlar" e se ele "não tem mulher em casa, encontra mulher na rua”. A construção cultural de gênero e patriarcado sempre colocaram a mulher a "serviço sexual do homem", estando submissa a ele, que é considerado o "ativo" social e sexual nas relações que controla a sexualidade feminina e a empurra para a reprodução, retirando-lhe o direito ao prazer. Alia-se ao fato de que a construção do gênero feminino também abstém a mulher de informações e afirmações sobre vivência da sexualidade (CARIDADE; MACHADO, 2008).

A literatura também mostra que a violência sexual no âmbito dos relacionamentos íntimos se manifesta na objetificação sexual da mulher, que é uma situação de opressão e desigualdade. A objetificação sexual é o processo primário de sujeição das mulheres, pois nas representações masculinas, a mulher continua a ser considerada como um objeto que se deseja adquirir (e depois exibir), mais do que como um sujeito com o qual se estabelece uma relação (DANTAS-BERGER; GIFFIN, 2005).

Considera-se estupro nas relações íntimas a violência sexual empregada contra a mulher na união afetiva em qualquer instância, praticada pelo seu próprio parceiro, mediante o uso de qualquer forma de violência (BARBOSA; TESSMANN, 2014). Os indicadores de vitimização sexual entre as estudantes universitárias são três vezes mais elevados do que os registados na população em geral (CARIDADE; MACHADO, 2008).

Observa-se que a violência psicológica antecede o estupro nas relações íntimas. Quando não consentido, o agressor usa de intimidações, desmoralizações e manipulação emocional para conseguir seu objetivo e a vítima cede ao desejo do agressor, temendo a agressão física ou por entender que por estar em uma relação, tem como obrigação fazer sexo (DANTAS-BERGER; GIFFIN, 2005). 
Alguns questões podem dar legitimidade as formas de violência citadas anteriormente. Oliveira e outros autores (2016) explicam que o ciúme e a infidelidade são fatores que justificam as agressões físicas entre jovens. Tal legitimidade encontra respaldo em normas de gênero que se expressam na violência como construção da masculinidade. O ciúme provocado pela infidelidade, real ou suposta, é apontado como principal disparador dos conflitos no namoro.

0 ciúme é percebido como negativo pelos jovens somente quando é considerado exagerado. Algumas pessoas são temerosas de que seus parceiros encontrem outros parceiros potencialmente mais atraentes e gratificantes do que elas, e dessa forma, alimentam uma insegurança afetiva (ALMEIDA; RODRIGUES; SILVA, 2008; CANEZIN; ALMEIDA, 2015; COSTA et al., 2014; OLIVEIRA et al., 2016). Mulheres são mais vitimizadas de diversas formas por conta do ciúme romântico, mas raramente dão queixa das agressões que sofrem. $O$ ciúme sexual masculino é um dos fatores de risco para que a mulher seja submetida a várias formas de violência pelo parceiro (SMEHA; OLIVEIRA, 2013; CENTEVILLE; DE ALMEIDA, 2014).

A construção da masculinidade, sendo permeada pela violência se expressa nos relatos de meninos e meninas quando qualificam a agressão física como algo intrínseco ao ser homem e percebem-na como algo mais praticado pelos namorados contra suas parceiras do que o contrário. Nesse contexto, sentir-se traído (nem sempre se tem evidência da infidelidade) é considerado bastante grave pelos jovens do gênero masculino, para quem a "traição" seria uma forma de humilhação, podendo provocar atitudes impulsivas e violentas. Porém, a crença de que ser infiel é da "natureza do homem" também persiste no imaginário feminino (OLIVEIRA et al., 2016).

Quanto aos motivos que mantém um jovem em um relacionamento íntimo abusivo, esses podem ser os mais diversos. Souza e Da Ros (2006) postularam que os motivos que as mantém em um relacionamento desse tipo perpassam por pressupostos voltados a construção do gênero feminino, a convivência com o medo, o tempo de relacionamento, a dependência financeira e a dependência emocional. Esta última seria um dos principais fatores de risco para a permanência em um relacionamento violento (BUTION; WECHSLER, 2016; SOPHIA; TAVARES; ZILBERMAN, 2007).

A violência, sendo uma demanda de ordem social, seus diversos tipos e desdobramentos deve ser prevenida e combatida. É necessário entender os jovens como alvos de intervenção de prevenção primária, como cidadãos ativos de mudança, capacitados para interiorizar novos conhecimentos, de desconstruírem mitos, de adquirirem competências, utilizarem e refletirem sobre estas eficazmente, de forma a alterar os seus comportamentos, quer a nível pessoal quer a nível comunitário (MANUEL, 2014; ABRAMO; PAULO, 2004; MANDELLI et al., 2011; ROSA et al., 2008).

Uma relação afetiva afeta o indivíduo de maneira global. Um relacionamento íntimo violento pode trazer consequências catastróficas. Os impactos da vivência desse tipo de relacionamento na vida de um jovem podem ser os mais diversos (MURTA et al., 2013). Além do mais os jovens que reportam experiência violenta nas relações afetivas estão mais propensos a elevados consumos de substâncias, a ter problemas de desempenho no emprego, na faculdade (levando a evasão acadêmica), ter problemas de controlo de peso, infeções sexualmente transmissíveis, gravidez indesejada, problemas com ansiedade. Numa situação mais extrema, a experiência de violência pode levar muitas vítimas a tentar, ou consumar o suicídio, ou até sofre feminicídio (MANUEL, 2014; GOMES, 2011). 


\section{CONCLUSÃO}

Observou-se que o jovem, como agente protagonista de sua história, também está sujeito a processos de violência na intimidade. A revisão narrativa da literatura mostrou que os signos culturais construídos pelo patriarcado ainda são amplamente introjetados pelos sujeitos e isso funciona como a base da violência nas relações íntimas. A revisão mostrou ainda que por conta da cultura patriarcal, mulheres são amplamente violentadas por homens, mas que também podem ser agentes de violência, ainda que em escala bem menor e que essa violência seja banalizada.

Jovens estão em um momento peculiar da construção social da humanidade. Uma das principais características da juventude é o ingresso na universidade e esse ingressar causa diversas modificações nos sujeitos, portanto, a atenção as relações de gênero na universidade pode ter efeitos positivos na prevenção a violência nas relações íntimas de jovens. $O$ trabalho preventivo deve focar na mudança dos signos que estimulam os processos violentos nas relações e não é algo a ser feito a curto prazo, mas requer o comprometimento de diversos atores sociais. Desde as políticas públicas, até jovens líderes articuladores. Por fim, espera-se que este trabalho possa auxiliar de alguma forma na compreensão do fenômeno da violência na intimidade de jovens e que possa servir de ponto de partida para futuras pesquisas.

\section{REFERÊNCIAS}

ABRAMO, H.; PAULO, P. Retratos da juventude brasileira. São Paulo: Instituto Cidadania; Fundação Perseu Abramo, 2004.

ADEODATO, V. G. et al. Qualidade de vida e depressão em mulheres vítimas de seus parceiros. Rev. Saúde Pública, v. 39, n. 1, p. 108-113, 2005.

ALDRIGHI, T. Prevalência e cronicidade da violência física no namoro entre jovens universitários do Estado de São Paulo - Brasil. Psicol. teor. prat., v. 6, n. 1, p. 105-120, 2004.

ALMEIDA, T.; RODRIGUES, K. R. B.; SILVA, A. A. O ciúme romântico e os relacionamentos amorosos heterossexuais contemporâneos. Estud. psicol., Natal, v. 13, n. 1, p. 83-90, 2008.

ALVIM, S. F.; SOUZA, L. Violência conjugal em uma perspectiva relacional: homens e mulheres agredidos/agressores. Psicol. teor. prat., v. 7, n. 2, p. 171-206, 2005.

BARBOSA, C.; TESSMANN, D. F. Violência sexual nas relações conjugais e a possibilidade de configurar-se crime de estupro marital. Judiciare, v. 6, n. 1, jun. 2014.

BARREIRA, A. K.; LIMA, M. L. C.; AVANCI, J. Q. Coocorrência de violência física e psicológica entre adolescentes namorados do recife, Brasil: prevalência e fatores associados. Ciênc. saúde coletiva, v. 18, n. 1, p. 233-243, 2013. 
BERTOLDO, R. B.; BARBARA, A. Representação social do namoro: a intimidade na visão dos jovens. PsicoUSF, v. 11, n. 2, p. 229-237, 2006.

BESERRA, M. A. et al. Prevalência e características da violência no namoro entre adolescentes escolares de Portugal. Esc. Anna Nery, v. 20, n. 1, p. 183-191, 2016.

BRASIL. Estatuto da juventude: atos internacionais e normas correlatas. Brasília: Senado Federal, Coordenação de Edições Técnicas, 2013

BUTION, D. C.; WECHSLER, A. M. Dependência emocional: uma revisão sistemática da literatura.

Est. Inter. Psicol., v. 7, n. 1, p. 77-101, 2016.

CANEZIN, P. F. M.; ALMEIDA, T. O ciúme e as redes sociais: uma revisão sistemática. Pensando fam., v. 19, n. 1, p. 142-155, 2015.

CARIDADE, S.; MACHADO, C. Violência na intimidade juvenil: Da vitimação à perpetração. Aná.

Psicológica, v. 24, n. 4, p. 485-493, 2006.

CARIDADE, S.; MACHADO, C. Violência sexual no namoro: relevância da prevenção. Psicologia, v. 22, n. 1, p. 77-104, 2008.

CENTEVILLE, V.; DE ALMEIDA, T. Ciúme romântico e a sua relação com a violência. Psicologia Revista, v. 16, n. 1/2, p. 73-91, 2014.

COELHO, E. B. S. Violência por parceiro íntimo: definições e tipologias. Florianópolis: Universidade Federal de Santa Catarina, 2018.

CONTINI, M. L. J.; KOLLER, Sílvia Helena. Adolescência e psicologia: concepções, práticas e reflexões críticas. Rio de Janeiro: Conselho Federal de Psicologia, 2002.

COSTA, C. B.; CENCI, C. M. B. A relação conjugal diante da infidelidade: a perspectiva do homem infiel. Pensando fam., v. 18, n. 1, p. 1934, 2014.

COSTA, N. et al. 0 ciúme está relacionado ao amor: Contribuições de uma perspectiva analíticocomportamental. Perspectivas, v. 5, n. 1, p. 40-48, 2014.

DANTAS-BERGER, S. M.; GIFFIN, K. A violência nas relações de conjugalidade: invisibilidade e banalização da violência sexual? Cad. Saúde Pública, v. 21, n. 2, p. 417-425, 2005. 
DE JESUS, J. S. O. Ficar ou namorar: um dilema juvenil. Psic, São Paulo, v. 6, n. 1, p. 67-73, 2005.

DIXE, M. A. C. R. et al. A Violência de Gênero na Relação de Namoro em Estudantes do Ensino Superior: Práticas e Comportamentos de Violência. IC, p. 978-989, 2010.

\section{GIL, A. C. Como elaborar projetos de pesquisa. São Paulo: Atlas 2002.}

GOMES, R. Invisibilidade da violência nas relações afetivo-sexuais. In: MINAYO, M. C. S.; ASSIS, S. G.; NJAINE, K. (Org.). Amor e violência: um paradoxo das relações de namoro e do 'ficar' entre jovens brasileiros. Rio de Janeiro: Editora FIOCRUZ, 2011. p. 141-151.

GUARESCHI MATTES, E.; FACCO ROCHA, N. Adolescentes e os relacionamentos abusivos: a tendência a se concretizar em casos de violência doméstica contra a mulher. Seminário Internacional Demandas Sociais e Políticas Públicas na Sociedade Contemporânea, 13, UNISC. Anais [...], Santa Cruz do Sul, 2016.

JUSTO, J. S. O "ficar" na adolescência e paradigmas de relacionamento amoroso da contemporaneidade. Rev. Dep. Psicol., UFF, v. 17, n. 1, p. 61-77, 2005.

LEVY, L.; GOMES, I. C. Relação conjugal, violência psicológica e complementaridade fusional. Psicol. clin., v. 20, n. 2, p. 163-172, 2008

KRUG, E. et al. (Ed.). World report on violence and health. Geneva: World Health Organization, 2002.

MANDELLI, M. T.; SOARES, D. H. P.; LISBOA, M. D. Juventude e projeto de vida: novas perspectivas em orientação profissional. Arq. bras. psicol., v. 63, n. spe, p. 49-57, 2011.

MANUEL, S. C. G. A violência no namoro entre jovens adultos. 2014, 53f. Dissertação (Mestrado em Educação para a Saúde) - Universidade do Porto, Porto, 2014.

MOURA, L. B. A. et al. Violências contra mulheres por parceiro íntimo em área urbana economicamente vulnerável, Brasília, DF. Rev. Saúde Pública, v. 43, n. 6, p. 944-953, 2009.

MURTA, S. G. et al. Prevenção à violência no namoro e promoção de habilidades de vida em adolescentes. Psicol. USP, v. 24, n. 2, p. 263-288, 2013.

OLIVEIRA, G. C. C.; PAES M. S. L. Violência de gênero contra a mulher: a vivência deste fenômeno. Revista Enfermagem Integrada, v. 7, n. 1, 2014. 
OLIVEIRA, Q. B. M. et al. Violência Física Perpetrada por Ciúmes no Namoro de Adolescentes: Um recorte de Gênero em Dez Capitais Brasileiras. Psic.: Teor. e Pesq., v. 32, n. 3, e32323, 2016.

PEREZ, T. S.; PALMA, Y. A. AMAR AMORES: O poliamor na contemporaneidade. Psicol. Soc., v. 30, p. e165759, 2018.

PIZZAI, L.; SILVA, R. C.; BELLO, S. F.; HAYASHI, M. C. P. I. A arte da pesquisa bibliográfica na busca do conhecimento. RDBCl: Revista Digital de Biblioteconomia e Ciência da Informação, v. 10, n. 1, p. 53-66, 2012.

PRODANOV, C. C.; DE FREITAS, E. C. Metodologia do trabalho científico: métodos e técnicas da pesquisa e do trabalho acadêmico. Editora Feevale, 2013.

REIS, E. A.; REIS, I. A. Análise descritiva de dados: síntese numérica. Belo Horizonte: UFMG, 2002.

RIBEIRO, F. M. L. et al. Entre o 'ficar' e o namorar: relações afetivo-sexuais. In: MINAYO, M. C. S.; ASSIS, S. G.; NJAINE, K. (Org.). Amor e violência: um paradoxo das relações de namoro e do 'ficar' entre jovens brasileiros. Rio de Janeiro: Editora Fiocruz, 2011. p. 55-86.

ROSA, A. G. et al. A violência conjugal contra a mulher a partir da ótica do homem autor da violência. Saude soc., v. 17, n. 3, p. 152-160, 2008.

ROSA, L. W.; FALCKE, D. Violência conjugal: compreendendo o fenômeno. Rev. SPAGESP, v. 15, n. 1, p. 17-32, 2014.

ROTHER, E. T. Revisão sistemática X revisão narrativa. Acta paul. enferm., v. 20, n. 2, p. v-vi, 2007.

SCHUCH, P. AIDS e Sexualidade entre Universitários Solteiros de Porto Alegre: um estudo antropológico. In: DUARTE, L. F. D.; LEAL, O. F. Doença, sofrimento, perturbação: perspectivas etnográficas. Rio de Janeiro: Editora FIOCRUZ, 1998. 210p.

SILVA, L. L.; COELHO, E. B. S.; CAPONI, S. N. C. Violência silenciosa: violência psicológica como condição da violência física doméstica. Interface, Botucatu, v. 11, n. 21, p. 93-103, 2007.

SMEHA, L. N.; OLIVEIRA, M. V. Os relacionamentos amorosos na contemporaneidade sob a óptica dos adultos jovens. Psicol. teor. prat., v. 15, n. 2, p. 33-45, 2013.

SOARES, J. S. F.; LOPES, M. J. M.; NJAINE, K. Violência nos relacionamentos afetivo-sexuais entre adolescentes de Porto Alegre, Rio Grande do Sul, Brasil: busca de ajuda e rede de apoio. Cad. Saúde Pública, v. 29, n. 6, p. 1121-1130, 2013. 
SOPHIA, E. C.; TAVARES, H.; ZILBERMAN, M. L. Amor patológico: um novo transtorno psiquiátrico? Rev. Bras. Psiquiatr., v. 29, n. 1, p. 55-62, 2007.

SOUZA, P. A.; DA ROS, M. A. Os motivos que mantêm as mulheres vítimas de violência no relacionamento violento. Revista de Ciências Humanas, EDUFSC, n. 40, p. 509-527, 2006. 
2 Psicólogo; Especialista em Terapia Cognitivo Comportamental; Mestre em Psicologia Social. Universidade Federal do Amazonas, FAPSI - Faculdade de Psicologia. E-mail: dancerdeira01@gmail.com

3 Psicóloga; Mestre e Doutora em Psicologia pela UnB; Professora Associada da Universidade Federal do Amazonas - UFAM; Professora do Programa de Pós-Graduação em Psicologia da. Universidade Federal do Amazonas UFAM, FAPSI - Faculdade de Psicologia. E-mail: iolete. silva@gmail.com

4 Psicólogo; Doutor em Saúde Pública - Saúde da Criança e da Mulher, com ênfase em Sexualidade, Reprodução, Gênero e Saúde, pela Fiocruz (IFF-RJ); Professor Adjunto na Escola Superior de Ciências da Saúde - (ESA/UEA); Professor no Programa de Mestrado Profissionalizante em Saúde da Família (Abrasco-Fiocruz). E-mail: eduhonorato@ hotmail.com

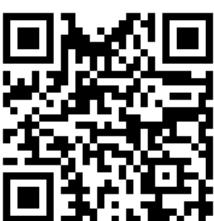

A autenticidade desse artigo pode ser conferida no site https://periodicos. set.edu.br

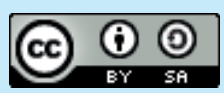

Este artigo é licenciado na modalidade acesso abertosob a Atribuição-Compartilhalgual CC BY-SA GRUPO
TIRADENTES
Inspirando o futuro

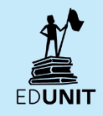

